\title{
LAS CADENAS DE TELEVISIÓN ESPAÑOLAS FRENTE AL DEBATE DEL 13J: ESTRATEGIAS DE PROGRAMACIÓN Y AUDIENCIA SOCIAL
}

\section{Spanish Television Channels and the 13-J Election Debate: Programing Strategies and Social Audience}

\author{
Marta SAAVEDRA LLAMAS \\ Profesora, directora del Departamento de Comunicación \\ Universidad Nebrija, España \\ E-mail: mmsaavedr@nebrija.es \\ (D) https://orcid.org/0000-0002-7762-9996
}

\section{Leticia RODRÍGUEZ FERNÁNDEZ}

Profesora, directora del Grado en Comunicación Corporativa, Protocolo y Organización de Eventos Universidad Nebrija, España

E-mail: mlrodrigu@,nebrija.es

(D) https://orcid.org/0000-0002-7472-5472

Fecha de recepción del artículo: 08/05/2018

Fecha de aceptación definitiva: 06/07/2018

\begin{abstract}
RESUMEN
El debate televisivo supone un factor decisivo en las campañas de comunicación política, más si se tiene en cuenta que las cadenas arbitran estrategias de audiencia social que provocan la transmedialidad del mensaje. El candidato, líder político televisivo, consigue impactar en una audiencia superior a la expuesta a las herramientas propagandísticas y puede conseguir una posición aventajada en el reparto de votos. El debate político entendido como contenido informativo y en directo es potencialmente atractivo para la audiencia tradicional y social y de ahí que las cadenas de televisión estructuren estrategias de programación y audiencia social para competir por el mayor número de espectadores. Esta investigación analiza la propuesta transmedia de La 1 de TVE, Antena 3, Telecinco y La Sexta ante el debate pre-electoral del 13 de junio de 2016. Todas las cadenas aprovecharon el impacto social del debate en mayor o menor medida, alcanzando una audiencia acumulada del 47\% y 1,8 millones de tuits. Las conversaciones se canalizaron a través de hashtag, hubo participación de los emisores oficiales, incluidos los líderes políticos, e integración de pantallas.
\end{abstract}

Palabras clave: Televisión; Redes Sociales; Audiencia Social; Debate electoral; Comunicación política; Transmedia

\begin{abstract}
The television debate represents a decisive factor in political communication campaigns, and even more so if we consider that the television channels arbitrate social audience strategies that cause the message to be transmedia. The candidate, a television political leader, is able to impact on an audience that is larger than the one exposed to the propagandistic tools, and they can obtain an advantageous position in the distribution of votes. The political debate, understood as informative and live content, is potentially attractive to the traditional and social audiences and hence, the television channels structure programming strategies and social media to compete for the largest number of
\end{abstract}


viewers. This research analyzes the transmedia proposal of La 1 of TVE, Antena 3, Telecinco and La Sexta before the pre-electoral debate of June 13th, 2016. All television channels benefit from the social impact of debate to a greater or lesser extent, achieving an accumulate audience of $47 \%$ and 1.8 million of tweets. Conversations were channeled through hashtags, and there was participation from official broadcasters, including political leaders, and screen integration.

Key words: Television; Social Networks; Social Audience; Electoral debate; Political Communication; Transmedia.

\section{INTRODUCCIÓN}

Los debates políticos televisivos tienen un fuerte impacto en la audiencia española desde la inauguración de este formato, de corte informativo y emitido en directo. El primer encuentro televisado se celebró el 25 de mayo de 1993, reunió a González (PSOE) y Aznar (PP) y alcanzó un 61,8\% de share. Desde entonces, todos los encuentros han tenido un fuerte posicionamiento, siendo el menos seguido el disputado el 7 de diciembre de 2015 entre Sáenz de Santamaría, Sánchez, Iglesias y Rivera (PP, PSOE, Podemos y Ciudadanos, respectivamente), que anotó, aun así, un destacado 48,2\%.

Esto provoca el interés de las cadenas de televisión y la estrategia de los grupos audiovisuales no solo se cimienta, hoy en día, en los contenidos de la primera pantalla, sino que procura incorporar a la audiencia social y mantener un visionado multipantalla a través de un relato transmedia.

La cadena busca diferenciación, posicionamiento y share. Y es que el debate político tiene, también, un buen comportamiento en redes, como ya indicaron Buschow, Schneider y Ueberheide (2014), lo que permite arriesgar en la estrategia transmedia de las televisiones. GómezDomínguez, Besalú-Casademont y Guerrero-Solé (2016) defienden que el debate televisivo tiene más facilidad que otros formatos para trasladar su discusión al metamedio y Halpern, Quintas-Froufe y Fernández-Medina (2016) sentencian que el contenido informativo y el humorístico es el que más actividad social dispara.

En relación a la audiencia social, su definición ya está asentada. En 2014, González-Neira y Quintas-Froufe la definieron como el número de individuos que realizan alguna mención sobre un contenido televisivo en una red social determinada. Twitter se ha posicionado como la red principal en este universo por su fácil uso, por permitir el comentario en tiempo real respecto al visionado, fomentar la interacción con otros usuarios, con el propio programa y sus protagonistas (presentadores, concursantes, actores, directores, cadena, marcas patrocinadoras...) y facilitar el comentario en un espacio idóneo a través de los hashtags creados de manera oficial o por los propios seguidores (Orihuela, 2011; Castelló, 2013; Rodríguez Breijo y Pestano, 2013; Saavedra y Rodríguez, 2016).

La audiencia social supone una oportunidad de crecimiento para medios y marcas, incluidos los partidos políticos. Los espectadores quieren participar en el nuevo entorno televisivo y el medio debe aprovechar esta actividad para acercarse a su público, ampliar el impacto de sus productos e idear nuevas fórmulas publicitarias combinadas que seduzcan a los anunciantes (Saavedra y Rodríguez, 2016c). La televisión se reinventa progresivamente y la experiencia de visionado se enriquece, pasa a ser multipantalla, multiplataforma, multisensorial y multitarea.

Esta interacción entre el contenido televisivo y los sentimientos de los usuarios favorece la transmisión de consignas políticas. Al final, los debates políticos televisivos son un pilar importante en la transmisión del mensaje dentro de una campaña electoral ya que aportan información sobre el candidato y el programa y está presente la configuración de la decisión de voto (Herrero y Benoit, 2011). Los partidos emiten su mensaje ante un segmento del electorado mucho mayor al expuesto a la propaganda electoralista y, ahora, con la participación de las redes sociales el alcance se multiplica. 
En los debates políticos televisivos se observa el proceso de mediatización de la política que provoca que sean los medios el principal motor de consulta del ciudadano ante la toma de decisiones electorales (Martínez-Pandiani, 2014). Este autor considera que el debate político televisivo atiende a otros cuatro procesos sociológicos: audiovisualización, dada la preponderancia de ese formato; espectacularización, ya que la televisión prioriza el entretenimiento, la carga emocional y la puesta en escena; personalización, en el sentido de que prima al candidato, y marketinización, ya que los partidos utilizan herramientas comerciales en la transmisión de los mensajes.

Si atendemos al debate televisivo actual, acompañado de una estrategia social transmedia, podemos incorporar una sexta dimensión, que denominaremos socialmediatización de la política, ya que medios y partidos hacen uso de las redes sociales para maximizar el alcance de sus propuestas. Quevedo, Portalés y Berrocal (2016) indican que los partidos, sobre todo, usan las redes sociales para adquirir presencia, lanzar propuestas electorales, solicitar el voto y expresar agradecimiento.

Luengo (2011), que inserta a los debates televisivos en la fase de modernización y personalización de las campañas, defiende efectos inmediatos: situación estratégica de los candidatos y ampliación de la atención mediática hacia el ganador, lo que podría traducirse en términos de voto.

Se considera ganador al candidato que ha podido dar más información, imagen y defensa. Este último campo es arriesgado, ya que la defensa tiene como fin restablecer la imagen personal y política, pero se corre el riesgo de recordar a la audiencia el ataque (Téllez, Múñiz y Ramírez, 2010). Además, el candidato debe asumir las peculiaridades del, denominado por Berrocal (2004), líder político televisivo, que pasan por la asunción del personaje de actor en la narrativa política, la capacidad transformadora, lo que conlleva un discurso lógico, racional y emocional, la imposición de la propaganda sobre el programa, el conocimiento del medio audiovisual, la tenencia de una imagen atractiva y creíble y el seguimiento a los medios que, dependiendo de su neutralidad, reforzarán o atacarán la estrategia política.

Trent y Friedenberg (2008), por su parte, analizan los contenidos televisivos de carácter preelectoral en dos áreas: spot positivos y negativos. En los primeros se resalta al candidato, que se enlaza con motivos positivos para el electorado, importantes de cara a su predisposición de voto. En los segundos se produce la descalificación del candidato, tratándolo de situar en una posición contraria a los intereses de los ciudadanos. La estrategia que se utilice en televisión dependerá, sobre todo, de la posición de la que parta el candidato en el arranque de la campaña o en el momento concreto de la emisión. Las redes sociales pueden, de nuevo, aportar información al partido de cuál es el sentimiento de la audiencia social antes, durante y después de la retransmisión para poder modular su comportamiento (Rodríguez y Saavedra, 2017).

\section{Metodología}

Esta investigación analiza la programación de las cadenas de televisión españolas generalistas en el debate pre-electoral del 13 de junio de 2016. Plantea, como objetivo general, analizar si esta programación está acompañada de una estrategia social transmedia que aglutina las plataformas y pantallas del medio y promueve la participación de la audiencia social en la emisión.

Además, plantea una serie de objetivos específicos como observar la estrategia de programación antes, durante y después del debate político del 13J para comprender la táctica completa de la cadena, examinar si existe estrategia de audiencia social y si las cadenas trasladan la táctica en redes a la primera pantalla, descubrir qué plataformas se integran en la acción transmedia, aportar datos de audiencia tradicional y social del debate del 13J para observar su posible trascendencia en la campaña política y corroborar si es un contenido interesante para las cadenas de televisión, comparando los resultados con otros debates de la televisión española. 
El estudio comprende dos fases metodológicas: una revisión documental relacionada con el objeto de estudio y un análisis de contenido de la programación de las cadenas de televisión seleccionadas, a partir de un patrón de observación. Explicamos a continuación estas dos etapas de investigación.

En primer lugar, abordamos la revisión documental de la literatura científica relacionada con nuestro objeto de estudio. Por un lado, atendimos las investigaciones previas que analizan las estrategias social-transmedia de las cadenas de televisión españolas para delimitar un marco de actuación y analizar si la táctica establecida se traslada o no a la emisión de debates electorales. Revisamos los trabajos de Álvarez Monzoncillo (2011), Orihuela (2011), Castelló (2013), Rodríguez Breijo y Pestano (2013), González-Neira y Quintas-Froufe (2014 y 2015) o Saavedra y Rodríguez (2016), entre otros. Por otro lado, revisamos las investigaciones sobre la utilización de la televisión, y concretamente del debate político, en las campañas electorales españolas para entender la dimensión de este contenido y la posible utilización de la retrasmisión por parte de los partidos políticos. Descubrimos que la producción científica se especializa más en el estudio del impacto de la televisión en las campañas electorales y en el uso del candidato/partido del debate televisivo que en la configuración de una estrategia por parte de las cadenas de televisión. Hemos utilizado los trabajos de Berrocal (2004), Trent y Friedenberg (2008), Téllez, Múñiz y Ramírez (2010), Luengo (2011), Herrero y Benoit (2011) y Martínez Pandiani (2014). También hemos atendido, de forma complementaria, los trabajos que analizan el uso de Twitter en las campañas pre-electorales, sobre todo, cuando los partidos utilizan las redes en relación a sus apariciones televisivas (Buschow, Schneider y Ueberheide, 2014; Gómez-Domínguez, Besalú-Casademont y Guerrero-Solé, 2016; Quevedo, Portalés y Berrocal, 2016 o Rodríguez y Saavedra, 2017).

Superada esta fase documental, procedimos, en segundo lugar, al análisis de contenido de la programación televisiva seleccionada.

Nuestra muestra contempla las cuatro cadenas generalistas de ámbito nacional, pertenecientes a los tres grupos de comunicación mejor posicionados de nuestro país (RTVE, Atresmedia y Mediaset), es decir: La 1 de TVE, Antena 3, Telecinco y La Sexta. Cabe apuntar que 17 canales emitieron el debate del 13J, pero redujimos la muestra a los cuatro canales principales de nuestro mercado, eliminando La 2 de TVE y Cuatro porque no interrumpieron su programación habitual para emitir el encuentro político entre los cuatro candidatos al Gobierno en las Elecciones Generales del 26 de junio.

Analizamos la parrilla de contenidos relacionada con el debate de estos cuatro canales en la franja de access, prime time y late night. El ejercicio se desarrolla, por tanto, desde las 20:00 horas del 13 de junio a las 02:00 horas del 14.

El patrón de análisis se configura tras el estudio previo de las autoras, que en trabajos anteriores modelizan los pilares fundamentales de las estrategias de audiencia social de las cadenas de televisión. Saavedra y Rodríguez (2016c), tras la revisión de las acciones relacionadas con el impulso de la audiencia social por parte de las cadenas españolas de 2014 a 2017, enumeran una serie de tácticas recurrentes en la televisión, que incluimos a continuación y que configuran los ítems de análisis:

1. Uso de un hashtag propio para canalizar la conversación social en torno al contenido y a la cadena por parte del programa y/o grupo de comunicación. Sobreimpresión de la etiqueta en la pantalla principal.

2. Utilización en la conversación social de emisores oficiales que aviven el flujo informativo, interactúen con los usuarios y fomenten el seguimiento de los mismos. Ampliación de la cartera de emisores oficiales: las cadenas no solo utilizan las cuentas de Twitter institucionales, sino las propias del programa en cuestión y de los agentes o talents que participan en los mismos. 
3. Escucha activa y rastreo de la conversación social en la primera pantalla. El programa incluye en la plataforma principal un seguimiento de la conversación en redes sociales ya sea en directo, con una sección específica o dentro de la intervención de un colaborador, o sobreimpresionando datos en pantalla.

4. Creación de contenido digital específico. La web del programa y/o cadena genera y difunde material extra que fomenta el intercambio de opiniones y activa la conversación social. Asimismo, ello provoca sinergias entre las plataformas utilizadas.

5. Integración de las plataformas, conectividad y traslación de contenido entre las pantallas: televisión, web, redes sociales y aplicaciones móviles.

Sobre el aspecto 5, cabe indicar que no solo se analiza la programación de las cadenas, sino la conversación social en Twitter dentro de la etiqueta propuesta, el site de cada canal y las aplicaciones móviles derivadas.

\section{RESUltados: OfERTA Y CONSUMO TELEVISIVO EN EL 13J}

Los españoles, en 2016, vieron 233 minutos de televisión al día (Barlovento Comunicación, 2017). Aunque el consumo se redujo un minuto respecto a 2015, este medio sigue siendo el más consumido, más si se tienen en cuenta otros sistemas de visionado como la televisión a la carta o bajo demanda. Además, la televisión de pago llegó a cuotas récord (del 18,8\% de share acumulado al 20,4\%) y se consolidó el negocio de las plataformas de distribución con Netflix, Yomvi (Movistar+), Wuaki, Filmin, Tucut y Nubeox. La CNMC (2017) indica que el conjunto de los operadores de streaming ya alcanza al $11 \%$ de los hogares españoles.

IAB Spain (2015) muestra que cuatro de cada diez internautas admiten ver menos televisión tradicional desde que consumen vídeo online pero que los contenidos más seguidos en el formato convencional son los informativos y los programas en directo.

No parece extraño que el debate electoral del 13 de junio -contenido informativo y en directo-, organizado por la Academia de la Televisión y emitido a través de una única señal por las cadenas generalistas La 1, Antena 3, Telecinco y La Sexta y por 13 temáticas y regionales, consiguiera gran audiencia tradicional: 47\% de share y 21 millones de espectadores (Barlovento Comunicación, 2016).

Se trata del quinto debate electoral más visto de la historia de la televisión española. El primero enfrentó a José Luis Rodríguez Zapatero y Mariano Rajoy el 25 de febrero de 2008 y se difundió en 22 cadenas (Elecciones Generales del 9 de marzo); el segundo contenía la participación de Alfredo Pérez Rubalcaba y Mariano Rajoy y se emitió en 17 cadenas el 7 de noviembre de 2011 (Elecciones Generales del 20 de noviembre); el tercero vuelve a reunir a los dos primeros políticos, también se ofrece por 22 canales y se celebró el 3 de marzo de 2008; el cuarto, denominado 'El debate decisivo', fue un contenido exclusivo de Telecinco, que reunió a Felipe González y José María Aznar el 31 de mayo de 1993 (Elecciones Generales del 6 de junio).

El debate objeto de análisis, que corresponde a las Elecciones Generales del 26 de junio de 2016, tuvo buen comportamiento de audiencia social: 1,8 millones de tuits y 233.000 autores únicos.

\subsection{LA GESTACIÓN DEL DEBATE TELEVISIVO DEL 13J}

En las Elecciones Generales de 2015, celebradas el 20 de diciembre, no fue posible televisar un debate a cuatro entre los líderes políticos de los partidos, a priori, fundamentales.

El presidente del Gobierno, Mariano Rajoy, declinó las invitaciones de los medios de comunicación alegando que solo se enfrentaría al líder de la oposición, Pedro Sánchez. El debate entre los dos 
candidatos, denominado 'El cara a cara', tuvo lugar el 14 de diciembre, estuvo organizado por la Academia de Televisión y fue moderado por Manuel Campo Vidal. Fue difundido por 12 cadenas, entre las que no se localizaba Mediaset. Sumó 9,7 millones de espectadores y un share del 48,7\%. La Sexta fue la cadena más vista con 2.914 .000 espectadores y un 14,6\%. En audiencia social, se registraron 1.674.930 tuits de 261.556 autores únicos.

Dentro de estas fallidas elecciones, sí se logró un debate a cuatro, pero sin la presencia del líder del Partido Popular, que estuvo representado por Soraya Sáenz de Santamaría. La entonces portavoz gubernamental se enfrentó a Pedro Sánchez, candidato del PSOE; Albert Rivera, líder de Ciudadanos, y Pablo Iglesias, secretario general de Podemos. Tuvo lugar el 7 de diciembre en Atresmedia y alcanzó una audiencia de 9,2 millones de espectadores (48,2\%). En el campo social logró mejor participación que el caso anterior y sumó 2.491 .539 tuits de 304.733 autores.

Las Elecciones Generales del 26 de junio contaron con un cambio en la estrategia de comunicación del Partido Popular. Jorge Moragas, dirigente de la campaña, cuenta en esta fase de reinvención con The Messina Group, compañía de comunicación, redes sociales y análisis de datos que preparó las últimas campañas de Obama y Cameron. Las redes sociales -el PP utilizó sobre todo Facebookocuparon un papel fundamental, pero también la ampliación de la presencia en televisión de Rajoy.

Este nuevo planteamiento, y que la representación en las Cortes ya contara con Ciudadanos y Podemos, posibilitó el debate definitivo del 13J. Se pacta que el debate sea realizado por un consorcio periodístico y técnico multicadena formado por profesionales de RTVE, Atresmedia y Mediaset. Moderan el encuentro tres representantes: Ana Blanco de RTVE, Vicente Vallés de Atresmedia y Pedro Piqueras de Mediaset.

Es emitido por 17 cadenas, que reciben la señal institucional de la organización. Se celebra a partir de las 22:00 horas. El prime time es la franja de emisión que más espectadores, target comercial y comentarios en redes sociales registra (Saavedra y Rodríguez, 2016a).

\subsection{LA ESTRATEGIA SOCIAL Y DE CONTENIDOS DE LAS CADENAS GENERALISTAS}

Con un $50 \%$ del rating en juego, las cadenas generalistas plantearon distintas estrategias. Repasamos los pilares de las ofertas de programación, reseñando cómo organizaron su presencia en redes y si trasladaron la táctica social a la primera pantalla.

\subsubsection{LA PREVIA AL DEBATE}

La 1 planteó un programa previo al debate. Consistió en un especial en directo conducido por Ana Blanco, de 20:00 a 21:00 horas. Posteriormente, se dio paso a la segunda edición del Telediario. Se sobreimpresiona el hashtag \#Deb4teTVE, que llega a ser trending topic en Madrid a las 21:00 horas. Debemos apuntar la escasa legibilidad del texto y la dificultad de la etiqueta, que bloquea el recuerdo y retrasa la conversación. No obstante, fue positiva la continuidad de la misma en los espacios.

En cuanto al contenido social, la primera mención se registra en el primer programa, cuando anuncian que los candidatos irán acompañados por sus directores de comunicación y por los responsables de redes sociales. Dentro del segundo programa se conecta en directo con el Palacio Municipal de Congresos ante la llegada de los candidatos y se relatan sus últimos tuits. A las 21:45 horas se devuelve la señal al primer espacio que recuerda el despliegue de la cadena pública: edición multipantalla, ocho reporteros, vinculación entre las cuatro sedes de los partidos y vídeos de presentación de los candidatos.

Por su parte, la web de TVE, a la que dirigían parte de los tuits de la cuenta oficial, no lanzó su contenido especial hasta que arrancó el debate. Una vez lo hizo, ofrecía a la audiencia el minutado del

(C) Ediciones Universidad de Salamanca / CC BY - NC ND Fonseca, Journal of Communication, n. 17, 2017, pp. 125-136 
encuentro, galería de imágenes, contenido informativo y un comparador de programas. Cabe decir que la web sirvió, también, de soporte central de la estrategia digital de Radio Nacional de España, que sobre todo desde su primera emisora y la especializada en información (Radio 5) siguió el debate.

Antena 3 no alteró su programación habitual, aunque en la franja de emisión anterior al debate sobreimpresionó el anuncio 'Debate a 4 a las 22:00 horas'. A las 21:00 horas arrancó el informativo de Vicente Vallés desde el Palacio de Congresos. A pesar de que la pantalla estaba altamente manchada con rótulos relacionados con el encuentro y con un temporizador que simulaba la cuenta atrás, no se incluyó un hashtag, lo que retrasó la conversación social.

La web sí que mantuvo durante la jornada contenido especial: material relacionado con la cita y enlaces a programas vinculados como ‘El Hormiguero' de Pablo Motos con la visita de Rivera o 'Dos días y una noche' de Susana Griso con Sánchez.

Telecinco no interrumpe su programación, pero introduce el anuncio 'Debate 2016, 22:00 horas' en la pantalla. Aunque no oferta un espacio especial, sí que realiza un informativo apegado a las redes sociales. Para empezar, sobreimpresiona el hashtag \#EIDebateT5 y articula una sección específica para el seguimiento de las redes, que capitanea Isabel Jiménez, encargada de realizar una escucha activa.

Se lanza a la audiencia - en la pantalla principal, en la web y en las redes sociales- preguntas como ‘¿Quién cree que ganará el debate?’ y ‘¿Cambiará su voto?’ y se analiza la participación de los usuarios en comparación con otros momentos de alta conectividad social (final última edición de 'Gran Hermano’ y debut de España en la Eurocopa). En una segunda intervención, se dibuja la nube de términos ('cuatro', 'debate', 'elecciones'), se visualizan los últimos tuits de los candidatos y se repasa el número de seguidores en redes de los partidos. La primera posición de la gráfica la ocupa Podemos. La web mantiene interacción con el usuario y presenta un contenido especial.

La Sexta sí interrumpe su programación habitual con un especial de 'Al rojo vivo', denominado 'El debate de los líderes'. Se prolonga desde las 20:30 a las 22:00 horas, es conducido por Antonio García Ferreras y desde su arranque sobreimpresiona el hashtag \#13JdebateL6, que se convierte en trending topic en Madrid. En el faldón de la pantalla se insertan los tuits de los políticos y de sus partidos. Los tertulianos comentan la actividad social y Ana Pastor entrevista a Pablo de Páramo, director de campaña de Ciudadanos, e Íñigo Errejón, exnúmero dos de Podemos.

La web presenta la misma estructura que la de Antena 3 pero añade interesante contenido relacionado con las redes sociales: seguimiento infográfico en tiempo real del debate en Twitter a través del servicio de Graphext, aplicación 'La ciudad del voto' para monitorizar la conversación social de los votantes indecisos o lanzamiento de una 'tuiteca' para analizar las aportaciones sociales de los cuatro candidatos.

La 2 y Cuatro no modificaron su programación. La cadena pública emitió cine español y la segunda espada de Mediaset su dating show habitual que, curiosamente, sí colocó el hashtag \#FirstDates47 en la lista de tendencias nacionales.

\subsubsection{EMISIÓN DEL DEBATE}

A las 22:00 horas, las cadenas conectan con la señal institucional. Antena 3 y La Sexta unifican la producción.

En el primer bloque del debate, de 32 minutos, se trata fundamentalmente la situación económica y las propuestas de crecimiento y empleo. En esta parte, las estrategias sociales de las cadenas para fomentar la conversación son diferentes.

Antena 3 y La Sexta sobreimpresionan desde el inicio un hashtag propio (\#13JAntena3 y \#13debateL6, respectivamente) y se muestran activas en la conversación social con sus cuentas oficia-

(C) Ediciones Universidad de Salamanca / CC BY - NC ND Fonseca, Journal of Communication, n. 17, 2017, pp. 125-136 
les y desde las personales de los periodistas del grupo. En el caso de Antena 3, las cuentas más activas fueron@A3Noticias y la de Mónica Carrillo (@MonicaCarrillo). En relación a La Sexta: @sextaNoticias,@DebateAlRojoVivo y la cuenta de Ana Pastor (@_anapastor_).

En ambas cadenas, la conversación social contó con la intervención de los partidos políticos, siendo los más activos Izquierda Unida y Ciudadanos. En las cuentas oficiales de los servicios informativos se ofrecían los datos de Graphext sobre la evolución de la participación social. Finalizado el primer espacio, dieron paso a publicidad.

La 1 incorpora a las 22:28 horas el hashtag \#Deb4teTVE y las cuentas oficiales más activas fueron @24h_tve, @telediario_tve, @tve_tve y @rtve. Contaron con intervención política, sobre todo de @ahorapodemos. Tras el bloque, insertaron la valoración de los expertos y establecieron conexiones con reporteros, manteniendo la etiqueta activa en pantalla.

Telecinco no introduce hashtag propio en el primer bloque, aunque participa activamente en la conversación social a través de las etiquetas \#ElDebateT5 y \#Debate13J. Las cuentas más representativas fueron@telecincoes y@mediasetcom. La estrategia social se orquestó desde la web e incorporó actividad en otras redes sociales como Facebook. La cadena también da paso a publicidad tras el cierre del primer bloque.

El segundo bloque versó sobre la regeneración democrática y las políticas sociales. Ya todas las cadenas contaban con su hashtag sobreimpresionado (Telecinco lo inserta a las 22:40 horas). En el caso de La 1 de TVE, la cuenta más activa ahora es@tve_tve; en Atresmedia, @sextaNoche y @A3Noticias; y en Telecinco, @ telecincoes. Los dos grupos comerciales dan paso a la publicidad tras el espacio y TVE ofrece la estadística sobre la participación de los ponentes y el tiempo utilizado, aporta las primeras conclusiones, incluye imágenes del descanso y conecta en directo con las sedes de los partidos.

El tercer bloque, de política exterior, terminó a las 00:28 horas y en él la actividad social de las cuentas oficiales se redujo. Ninguna de las cadenas logró posicionar su hashtag en el ranking de tendencias nacionales; sí lo fue la etiqueta genérica \#debate13J. Al cierre, TVE ofreció el minutaje total utilizado por los candidatos y la cobertura de la salida. Antena 3 y La Sexta combinaron la publicidad con la señal de la salida. Telecinco emitió la despedida, pero, también, organizó una primera mesa de debate para analizar las aportaciones políticas.

Según Kantar Media, el minuto de oro en audiencia tradicional se registró a las 22:41 horas, alcanzándose una cifra de 11.888 .000 espectadores. En este momento, Rivera exigía igualdad entre comunidades. La audiencia social se atrasó y alcanzó el máximo de comentarios a las 23:38 horas (13.000 tuits por minuto), cuando Rivera acusó a Iglesias de recibir dinero de Venezuela. Se eleva la participación social en subtemas de financiación y corrupción.

Como hemos visto, los partidos políticos participan en la conversación social arrancada por las cadenas de televisión, es decir, forman parte de la estrategia social media de los canales. Replican y refuerzan en forma de tuit los discursos de los líderes de sus formaciones, aunque, en el caso del debate del 13J, de manera desigual.

Podemos y PSOE comparten más información y se muestran más interactivos con la comunidad, realizando un mayor número de retuits, mientras que PP y Ciudadanos se muestran más cautos en sus intervenciones. Tan solo Izquierda Unida integra a la audiencia social en su estrategia al planificar un juego específico que animaba al visionado del debate, incorporando el humor en su conversación.

No obstante, observamos que todas las formaciones son conscientes del papel de la audiencia social y animan al visionado del debate, aunque luego limiten su estrategia reproduciendo o reforzando con contenido audiovisual el discurso institucional de su formación. 


\subsubsection{Programación POSTERIOR}

Las cadenas programaron contenido relacionado tras la emisión del debate.

La 1 alargó su emisión hasta las 02:00 horas. En todo el trascurso del post-espacio mantuvo el hashtag, pero no hizo un seguimiento profundo de la participación social.

Antena 3 programó hasta la 01:30 horas el espacio ‘13J El Debate'. No mantuvo el hashtag sobreimpresionado durante toda la emisión, pero sí que rotuló en el faldón de la pantalla los tuits de los partidos. Fue la primera cadena en incorporar al late night a su representante en la moderación del encuentro, Vicente Vallés.

Telecinco emitió 'El debate a debate' hasta las 02:00 horas. No incorpora el hashtag, pero sí que realiza un seguimiento de la conversación social, volcando distintos datos: tímida conversación inicial -se refieren al ruido dentro de su etiqueta y cabe recordar que no estaba sobreimpresionada en pantalla en el arranque-, éxito global del espacio en redes en comparación con otros formatos exitosos y resultado de la encuesta lanzada en la web, que determina que el ganador del debate para los internautas es Sánchez, seguido de Iglesias, Rajoy y Rivera.

La Sexta ofertó 'ARV El debate de los líderes' hasta la 01:30 horas, retomando el espacio de la tarde. Sí mantuvo su hashtag. Ofreció los tuits de los políticos y aportó entrevistas a los directores de campaña, que relatan su comportamiento en redes durante el debate. Aunque no analiza el sentimiento de la audiencia social, sí que lanza a través de Twitter y de la web una encuesta, que determinan que el ganador del encuentro ha sido Iglesias, seguido de Rajoy (barómetro de La Sexta realizado por Invymark).

Este canal ofrece en sus plataformas digitales los resultados del estudio de Graphext que indica que la etiqueta más seguida fue la genérica y que los partidos publicaron durante el debate 13.496 tuits, concentrándose mayor actividad de las 23:00 a las 00:00 horas, cuando se analizaban temas sociales y de regeneración.

El hashtag genérico (\#debate13J) acaparó el 83,3\% de la actividad social y las etiquetas de las cadenas solo el 16,7\%, siendo La Sexta el canal mejor posicionado con un 12,5\% de los comentarios y un máximo de 2.000 tuits por minuto.

\subsubsection{RESULTADOS DE LAS ESTRATEGIAS TELEVISIVAS}

La Sexta fue la cadena que mejor posicionamiento obtuvo tanto en el rating tradicional como en el share social. Alcanzó a 2.602.000 espectadores, un 14,1\% de la audiencia y logró que su hashtag tuviera buen comportamiento con un $12,5 \%$ de los comentarios. Existe por tanto en este caso correspondencia entre el espectador tradicional y el social, que utilizó la segunda pantalla para completar información, aportar opinión o interactuar.

En las otras tres cadenas no hubo correlación entre las audiencias, pero también es cierto que la conversación social fue muy residual en las etiquetas de TVE, Antena 3 y Telecinco. En cuanto a número de espectadores, la segunda opción fue La 1 con el 13,2\%; en redes ocupa la tercera posición con un grueso del 1,4\% de los comentarios. La tercera opción fue Telecinco con el 12,1\% de los espectadores, pero en la conversación social ocupa el último puesto con el 1,3\% de los comentarios. Antena 3 es la cuarta opción para los espectadores con un 11\% y, en cambio, la segunda para los tuiteros, con una representación del 1,6\%. 


\section{CONCLUSIONES}

El debate político televisivo del 13J se convirtió en un éxito de audiencia para la televisión en general. El contenido alcanzó a la mitad de los españoles, como confirman los datos de share que indican que 21 millones de telespectadores siguieron el contenido. Sí es cierto que no despertó tanto interés como otros debates anteriores, pero las cadenas de televisión generalistas no pueden perder la oportunidad de impactar en un $47 \%$ de la audiencia.

La traslación del debate a las redes sociales también logró un fuerte impacto, con 1,8 millones de tuits. No obstante, no se alcanzaron las cifras de participación social del encuentro político anterior con los cuatro partidos candidatos, el del 7 de diciembre de 2015. Este debate recogió 2,4 millones de tuits. Se percibe así una caída del 33\%.

Por tanto, aunque el debate televisivo, de carácter político y pre-electoral, sigue teniendo gran trascendencia en las audiencias tradicionales y sociales, parece observarse una caída del interés del consumidor español que puede deberse a la concentración excesiva de este tipo de contenidos en las parrillas televisivas, debido a la peculiar situación política y a la repetición de las Elecciones Generales.

Tampoco se observa correlación entre la audiencia social y tradicional en cuanto al contenido de mayor interés. Mientras el espectador de televisión despegó cuando Rivera pidió la igualdad entre comunidades autónomas, el seguidor social apuntaló su participación en la disputa entre Rivera e Iglesias por la posible financiación de Venezuela. No obstante, son los temas económicos, de financiación y corrupción, los que levantan más polémica y, por tanto, alcanzan más audiencia y comentarios.

En relación a la estrategia de las cadenas de televisión analizadas, todas compitieron entre sí para intentar lograr un mejor posicionamiento; todas construyeron una estrategia de programación transmedia, conectando la pantalla principal con la participación en redes sociales, la web y las aplicaciones derivadas.

La 1 de TVE, Antena 3, Telecinco y La Sexta desarrollaron, por tanto, una estrategia social y conectada en la emisión del 13J. Las cuatro, aunque a diferentes niveles, incorporaron una etiqueta para canalizar la conversación social, utilizaron a sus emisores oficiales para avivar la conversación, realizaron un seguimiento de las redes, crearon contenido digital especial que supusiera un valor añadido para el usuario enriqueciendo su experiencia de visionado e integraron sus plataformas (primera pantalla, web, redes sociales y aplicaciones móviles).

En cuanto al uso de hashtag, las más aventajadas fueron TVE y La Sexta, que ya sobreimpresionan la etiqueta en el programa previo al debate. TVE pierde su posicionamiento al no mantenerla en el arranque del encuentro (la recupera pasados 28 minutos). Así, La Sexta se posiciona como tendencia televisiva más destacada: desde las 20:30 horas y de forma continuada promociona su vía de conversación. Además, la etiqueta de TVE es menos legible en pantalla y más difícil de cara al recuerdo. Aprueba el hashtag de la segunda cadena de Atresmedia: \#13JdebateL6 en vez de \#Deb4teTVE.

Los tres grupos de comunicación utilizaron sus cuentas oficiales en la conversación social, pero sí que es cierto que algunos de los talents con más seguidores de Atresmedia, y en especial de La Sexta, participaron activamente, lo que reporta beneficios a la estrategia social. Valga como ejemplo el caso de Ana Pastor con 1,88 millones de seguidores o Jordi Évole con 2,94. Y es que la multiplicación de emisores oficiales, amparados por la marca, dinamiza el flujo conversacional.

En el seguimiento a la conversación social, las más innovadoras fueron Telecinco y La Sexta. La primera introdujo una sección en los informativos y en el post-espacio. Se analizó la nube de tags, se comparó el debate con otros momentos televisivos de máximo impacto, se observó el comportamiento de las cuentas políticas y se lanzaron preguntas a la audiencia para favorecer el engagement. La Sexta, sin incorporar una sección específica, logró llevar el propio tema a la tertulia. La estrategia no estaba

(C) Ediciones Universidad de Salamanca / CC BY - NC ND Fonseca, Journal of Communication, n. 17, 2017, pp. 125-136 
tan estructurada, pero la cadena contó con el efecto remolque de la audiencia que les acompañó en la programación previa - Telecinco no contraprogramó-, y canalizó mejor a sus seguidores manteniendo activa y en pantalla la etiqueta -Telecinco incorpora su hashtag a las 22:40 horas-.

La Sexta aprovechó mejor las sinergias entre sus plataformas y fue la cadena que más contenido digital complementario ofreció a sus seguidores. Destaca el proyecto de gamificación 'La ciudad del voto', el lanzamiento de encuestas, la recuperación de una hemeroteca de tuits y la alianza con Graphext para la disposición de infografías en tiempo real.

Por su parte, los partidos políticos se beneficiaron de un formato que difunde el ideario, ensalza al candidato, promueve la denuncia y la defensa y recoge votos para la campaña. El líder ya no prestó toda su atención a la televisión, sino que al mismo tiempo trasvasó su mensaje en una suerte de pantallas. La transmedialidad del discurso televisivo sirve de altavoz a las consignas políticas que logran posicionarse en redes sociales, páginas webs y aplicaciones móviles.

Con la socialmediatización, el debate televisivo consigue una fuerza renovada que impacta, además, en un target más joven y complementario a la audiencia tradicional. Como indica el Estudio General de Medios (2017), la televisión impacta principalmente en un target de 45 a más de 65 años y, en cambio, Internet tiene más fuerza en el segmento poblacional de 14 a 44 años. Ambos medios se complementan y, por tanto, cuando se integran en una estrategia social transmedia hay una ampliación del perfil del seguidor. Así lo hemos observado en los tres debates del último periodo electoral: 2,5 millones de tuits en el debate del 7D, 1,8 en el 13J y 1,6 en el 14D.

El nuevo debate político televisivo, acompañado de una estrategia social trasmedia que pasa por una integración de pantallas, se confirma no solo como un puntal de la comunicación política, sino también como un escenario de innovación y negocio para la televisión.

\section{BiBLIOGRAFÍA}

AIMC (2017). Estudio General de Medios. Resumen General.

Álvarez-Monzoncillo, J. M. (2011). La televisión etiquetada: nuevas audiencias, nuevos negocios. Madrid, España: Fundación Telefónica-Ariel.

Barlovento Comunicación. (2017). Análisis Televisivo 2016. Madrid, España: Servicio de publicaciones. Barlovento Comunicación. (2016). Informe de audiencia debate electoral 13 junio 2016. Madrid, España: Servicio de publicaciones.

Berrocal, S. (2004). Una aproximación a la nueva retórica del líder político televisivo: acciones, cualidades y discurso. Doxa Comunicación, 2, 53-67.

Buschow, C., Schneider, B., Ueberheide, S. (2014). Tweeting television: Exploring communication activities on Twitter while watching TV. Communications, 39(2), 129-149.

Claes, F., Deltell, L. (2015). Audiencia social en twitter: Hacia un nuevo modelo de consumo televisivo. Tripodos, 36, 111-132.

Castelló, A. (2013). El uso del hashtags en Twitter por parte de los programas de televisión españoles. I Congreso Internacional de Comunicación y Sociedad Digital. 17, 18 y 19 de abril de 2013, Universidad Internacional de La Rioja.

CNMC. (2017). Informe Económico Sectorial de las Telecomunicaciones y el Audiovisual 2016. Madrid, España.

Gómez-Domínguez, P., Besalú-Casademont, R., Guerrero-Solé, F. (2016). Metamedios sociales y servicio público: el debate en Twitter de los programas factuales de BBC, RTVE y CCMA. El profesional de la información, 25(3), 384-394. 
González-Neira, A., Quintas-Froufe, N. (2014). Twitter, la televisión y la audiencia social. ¿Por qué triunfa un espacio en la audiencia social? En: http://www.foro2014.com/wp-content/uploads/2014/02/31.Gonz\%C3\%A1lez-Quintas.pdf

González-Neira, A., Quintas-Froufe, N. (Coords.). (2015). La participación de la audiencia en la televisión: de la audiencia activa a la social. Madrid, España: AIMC.

Halpern, D., Quintas-Froufe, N.; Fernández-Medina, F. (2016). Interacciones entre la televisión y su audiencia social. El profesional de la información, 25(3), 367-375.

Herrero, J. C., Benoit, W. (2011). Análisis funcional de los debates en las elecciones generales de 2008. Zer-Revista de Estudios de Comunicación, 14(27).

IAB. (2015). VI Estudio Anual de Redes Sociales. Madrid, España.

Luengo, Ó. G. (2011). Debates electorales en televisión: una aproximación preliminar a sus efectos inmediatos. Revista española de ciencia política, (25), 81-96.

Martínez-Pandiani, G. (2014). El impacto de la televisión en la comunicación política moderna. Signos universitarios, 25(1).

Orihuela, J. L. (2011). Mundo Twitter. Una guía para comprender y dominar la plataforma que cambió la red. Barcelona: Alienta Editorial.

Quevedo, R., Portalés, M., Berrocal, S. (2016). El uso de la imagen en Twitter durante la campaña electoral municipal de 2015 en España. Revista Latina de Comunicación Social, 71, 85-107.

Rodríguez, L.; Saavedra, M. (2017). Debate electoral 13-J: la audiencia social en la estrategia digital de los partidos políticos. Tripodos, 41, 173-191.

Rodríguez Breijo, V., Pestano, J. M. (2013). El monólogo Twitter: características de la participación de la teleaudiencia en los programas de opinión. Actas V Congreso Internacional Latina de Comunicación Social V CILCS, Universidad de La Laguna, diciembre de 2013.

Saavedra, M., Rodríguez, L. (2016a). Audiencia social: Una oportunidad para el medio televisivo y para la estrategia publicitaria. Telos, 103, 102-111.

Saavedra, M., Rodríguez, L., Barón, G. (2016b). Audiencia social en España: Estrategias de éxito en la televisión nacional. Icono 14, 13(2), 214-237.

Saavedra, M., Rodríguez, L. (coords.) (2016c). Audiencia social. Estrategias de comunicación para medios y marcas. Madrid, España: Editorial Síntesis.

Téllez, N., Múñiz, C., Ramírez, J. (2010). Función discursiva en los debates televisados. Un estudio transcultural de los debates políticos en México, España y Estados Unidos. Palabra-Clave, 13(2), 251-270.

Trent, J. S., Friedenberg, R. V. (2008). Political Campaign Communication: Principles and Practices. $\left(6^{\text {th }}\right.$, Ed.) Lanham, MD: Rowman \& Littlefield Publishers. 